\title{
Pandemia y precarización laboral en Argentina
}

Christian Castillo

\begin{abstract}
Resumén
El artículo articula la pandemia COVID-19 con la precarización laboral en Argentina. Destaca que entre las distintas estrategias elegidas por los gobiernos para enfrentar-el virus Argentina optó por la del Aislamiento Social, Preventivo y Obligatorio a partir del día 20 de marzo, poco después de las primeras muertes. Los resultados sanitarios obtenidos son presentados como relativamente exitosos por el gobierno de Alberto Fernández, en particular en comparación con lo ocurrido en Chile, Perú, Ecuador o Brasil, aunque están claramente por detrás de los obtenidos por Paraguay y Uruguay, países con menor cantidad de contagios y muertos en la región.
\end{abstract}

\section{Palabras clave}

Pandemia; Precarización; Argentina; COVID 19.

\section{Resumo}

O artigo articula a pandemia COVID-19 com a precarização no trabalho na Argentina. Destaca que, entre as diferentes estratégias escolhidas pelos governos para enfrentar o vírus, a Argentina optou pela de Isolamento Social Preventivo e Obrigatório a partir de 20 de março, logo após as primeiras mortes. Os resultados sanitários obtidos são apresentados como relativamente exitosos pelo governo de Alberto Fernández, particularmente em comparação com o que aconteceu no Chile, Peru, Equador ou Brasil, embora estejam claramente aquém dos obtidos pelo Paraguai e Uruguai, países com menos contágios e mortes na região.

\section{Palavras chave}

Pandemia; Precarização; Argentina; COVID 19.

\section{Pandemic and labor pre-care in Argentina}

\begin{abstract}
The article articulates the COVID-19 pandemic with labor pre-care in Argentina. It stands out that among the different strategies chosen by the governments to confront the virus, Argentina opted for that of Social, Preventive and Mandatory Isolation as of March 20, shortly after the first deaths. The health results obtained are presented as relatively successful by the government of Alberto Fernández, particularly com-
\end{abstract}


pared to what happened in Chile, Peru, Ecuador or Brazil, although they are clearly behind those obtained by Paraguay and Uruguay, countries with fewer contagions and deaths in the region.

\section{Keywords}

Pandemic; Labor pre-care; Argentina; COVID 19.

Artigo recebido em junho 2020

Artigo aprovado em agosto de 2020

Entre las distintas estrategias elegidas por los diferentes gobiernos para enfrentar la pandemia de coronavirus Argentina optó por la del Aislamiento Social, Preventivo y Obligatorio (ASPO) a partir del día 20 de marzo, poco después que se produjeron las primeras muertes. En lo que respecta al Área Metropolitana Buenos Aires (AMBA), que incluye a la Ciudad Autónoma de Buenos Aires y los municipios que la rodean pertenecientes a la Provincia de Buenos Aires ${ }^{2}$, donde se concentra casi un $40 \%$ de la población, la medida continúa rigiendo en momentos que escribimos estas líneas. Los resultados sanitarios obtenidos son presentados como relativamente exitosos por el gobierno de Alberto Fernández, en particular en comparación con lo ocurrido en Chile, Perú, Ecuador o Brasil, aunque están claramente por detrás de los obtenidos por Paraguay y Uruguay, los países con menos contagios y muertos de toda la región.

Al igual que ocurrió en muchos países, pero con el agravante de venir de una situación de estancamiento, la implementación del ASPO implicó una parálisis general de la economía argentina. El derrumbe para el mes de abril de 2020, el primero en el cual la medición registra íntegramente días de cuarentena, superó el 26,4\%. En sectores como la construcción la baja alcanzó casi un 90\%. Las proyecciones indican una caída anual que podría estar entre un 13 y un 15\%., solo comparable a lo ocurrido en la crisis de 2001-2002. Para la clase trabajadora 
esto ya ha significado una caída muy importante en sus condiciones de vida y de trabajo. Todas las condiciones previas de precarización laboral se agravaron. Las patronales han utilizado la emergencia para imponer una suerte de "reforma laboral de hecho". A pesar del discurso gubernamental las medidas estatales no han evitado esta situación.

Desde ya que la implementación de diversas formas de "precarización" y "flexibilización" laboral no son una novedad. Entre la dictadura militar que rigió entre 1976 y 1983 y las políticas neoliberales aplicadas en la década de los '90 del siglo XX, la clase trabajadora argentina, caracterizada previamente por un mercado de trabajo altamente formalizado desde mediados de la década de 1940, sufrió un proceso de precarización de envergadura, como parte de un fenómeno más general que tuvo lugar a nivel internacional. Entre las formas más habituales que adoptan la precarización y flexibilización laboral en el país tenemos: el trabajo no registrado; el ocultamiento de la relación de dependencia mediante la utilización del "monotributo"; los contratos de duración determinada; las tercerizaciones; la flexibilización de los convenios colectivos de trabajo; los contratos de "primer empleo", pasantía y leyes especiales; y los planes sociales con contraprestación laboral.

Desde 2004 el Observatorio de la Deuda Social (ODSA), dependiente de la Universidad Católica Argentina, realiza una encuesta que abarca a 5700 hogares centrada en el análisis de las condiciones de trabajo. El último informe, todavía no disponible en su totalidad al momento de escribir este artículo, analiza lo sucedido entre 2010 y 2019 en el mercado de trabajo en los principales centros urbanos de todo el país y se titula "Fragmentación y precariedad laboral en los trabajadores urbanos". De acuerdo con los adelantos publicados ${ }^{3}$, el informe afırma que en la última década casi se estancó la generación de empleo de calidad, lo que generó pequeñas variaciones de la desocupación y un incremento del subempleo inestable en la población de 18 años y más residente en las áreas urbanas. 
Durante esos años, disminuyó la proporción de trabajadores con pleno empleo de derechos (pasó del 43,8\% a 41,8\% del total de activos) y la desocupación cayó del 11,4\% al 10,6\%. Pero lo que, según los investigadores, es el dato más relevante de la década es el aumento del subempleo inestable, al realizar changas, trabajos temporarios o no remunerados, o siendo beneficiarios de programas de empleo con contraprestación, que trepó del 9,7\% en 2010 al 20,7\% en 2019. Según lo define el autor del informe, el investigador Eduardo Donza:

"El mayor problema es la precariedad laboral, el subempleo inestable. Lo que esto reafirma es que la situación en la Argentina con respecto al mercado de trabajo es estructural. Algunas políticas económicas pueden agravar o aliviar un poco la situación, pero hay cuestiones estructurales de las cuales no pudimos salir durante décadas".

A su vez, solo en abril la caída de empleos en el sector registrado de los trabajadores, el más protegido debido a la prohibición de los despidos, fue de 186.0004. En el sector informal los números son infinitamente superiores.

Veremos en este trabajo como ha repercutido esta situación de precarización en diferentes sectores de la clase trabajadora.

\section{Los que se quedaron sin ingresos}

Para la clase trabajadora argentina el ASPO tuvo implicancias muy diversas según el sector al que se perteneciera. La administración pública en sus distintos niveles (nacional, provincial y municipal) y los docentes de todos los niveles cesaron sus actividades presenciales y pasaron a desarrollar sus actividades por distintas formas de teletrabajo y virtualización forzosa o a estar licenciados, pero cobrando siempre el 100\% de sus salarios. El Ilamado "teletrabajo" también se aplicó en numerosas actividades del sector privado. También están quienes pertenecen a las actividades Ilamadas "esenciales" que siguieron tra- 
bajando. El número inicial de 24 actividades se fue incrementando con las actividades que fueron progresivamente exceptuadas, aunque en el caso del AMBA las nuevas restricciones establecidas entre el 1 y el 17 de julio volvieron a limitar actividades ${ }^{5}$ a solo 30 áreas. En algunas actividades privadas se pactaron suspensiones cobrando el $75 \%$ de los salarios, a partir de un acuerdo realizado entre la Unión Industrial Argentina (UIA) y la Confederación General del Trabajo (CGT), homologado por el gobierno nacional. Quienes más fueron golpeados son los que vivían de un ingreso diario y le perdieron a partir de la suspensión de la mayoría de las actividades económicas.

Previamente a la pandemia, Argentina ya presentaba tasas muy elevadas de trabajo no registrado, que llegaban al 35,9 \% de la fuerza laboral, con una distribución muy desigual según sector económico. Trabajo doméstico, trabajo rural, gastronomía, construcción, turismo, comercio, se encuentran entre las actividades con mayores índices de trabajo sin registrar. A su vez, en ocasiones también sin registro y otras veces registrados como "monotributistas" hay una amplia franja de trabajadores "por cuenta propia" que desempeñan las actividades más diversas. Con la implementación del ASPO se calcula que más de siete millones de trabajadores quedaron sin ingresos de un día para el otro. A ellos hay que sumar a quienes ya se encontraban desocupados y a los que son parte de la llamada "economía popular", trabajadores que reciben el plan "Argentina Trabaja" y son parte de alguna de las cooperativas de trabajo precario que se desarrollan en el marco de alguno de los distintos movimientos sociales.

Para intentar compensar la pérdida de ingresos en la mayoría de este sector, el gobierno lanzó el Ingreso Familiar de Emergencia (IFE), de $\$ 10.000$ mensuales por grupo familiar, a cobrarse siempre que se cumplieran una cantidad determinada de requisitos ${ }^{6}$. Los cálculos iniciales del gobierno estimaban que los beneficiarios serían entre 3 y 4 millones de personas. Lo cierto es que los inscriptos superaron los 12 millones y quienes lo terminaron recibiendo fueron casi 9 millones. La 
gran mayoría solo cobró, tras superar los tres meses del ASPO, solo la primera cuota, es decir apenas \$3.300 mensuales por grupo familiar (la segunda cuota está en proceso de cobro hasta finales de julio y se analiza si se pagará una tercera). En contraste con esta ayuda muy limitada, a las empresas se les pagó un 50\% de los salarios de todos sus empleados hasta dos salarios mínimos (\$33.000), incluida la planta gerencial, el programa Asistencia al Trabajo y la Producción (ATP), en abril, mayo y junio. Es así que, del total del gasto fiscal adicional realizado durante la pandemia, solo un 30\% fue destinado directamente a los trabajadores y sectores vulnerables mientras un 70\% estuvo destinado al rescate de los capitalistas.

La situación de millones que perdieron sus ingresos y una compensación muy limitada que apenas llegó a solo una parte de quienes la requerían, llevó a una saturación en la capacidad de los comedores populares para dar satisfacción a las necesidades alimentarias de los sectores más vulnerables de la población. Según datos del Ministerio de Desarrollo Social las primeras semanas del ASPO vieron un aumento de la demanda alimentaria de 8 a 11 millones de personas. En diciembre de 2019 los comedores populares certificados eran 3000 en todo el país, cifra que se incrementó hasta 5000 en la actualidad. Son los comedores que reciben fondos directos para la compra descentralizada de alimentos. A este número deben sumarse miles más de centros, ollas populares y comedores no registrados, que se nutren de alimentos provistos por los municipios, movimientos y organizaciones sociales, entidades religiosas y donaciones particulares?

Entre quienes se inscribieron para recibir el IFE se cuentan la gran mayoría de quienes habitan villas y asentamientos a lo largo y ancho del país, aproximadamente 1 millón de familias (unas 4 millones de personas). El Registro Nacional de Barrios Populares (RENABAP) dio cuenta de la existencia de 4416 urbanizaciones con estas características en todo el país, que sumadas ocupan un territorio superior al de la Ciudad Autónoma de Buenos Aires. Más de 1800 se concentran en 
la Provincia de Buenos Aires. Un barrio popular - de acuerdo con los parámetros del relevamiento realizado inicialmente en 2018 - es aquel donde viven al menos ocho familias agrupadas o contiguas, en el que más de la mitad de la población no cuenta con título de propiedad del suelo ni acceso regular a dos (o más) de los servicios básicos: red de agua corriente, red de energía eléctrica con medidor domiciliario y/o red cloaca ${ }^{8}$. Ni hablar del acceso a internet. Para muchas de estas familias, que viven en condiciones de hacinamiento, con tres o más personas por habitación, el cumplimiento del ASPO resulta muy complejo o directamente imposible, ya que la falta de recursos los obliga a tratar de realizar alguna actividad para garantizarse el ingreso, como la recolección y reciclado de residuos. También son múltiples las difıcultades de niños y adolescentes que habitan estos barrios para la realización de las actividades escolares virtuales de acompañamiento pedagógico. En el caso de la Ciudad Autónoma de Buenos Aires ocurrió que en la villa más populosa (40.059 personas según el censo de 2018), el Bario 31 "Carlos Mugica", faltó el agua durante 12 días, cuestión que favoreció la generalización de los contagios de COVID y provocando la muerte de activistas sociales que habían denunciado la situación y terminaron siendo víctimas de la enfermedad, como Ramona Medina de la agrupación La Garganta Poderosa, de fuerte presencia en las villas de la Capital. Salvo en los casos puntuales donde los contagios tomaron estado público y forzaron la necesidad de una intervención estatal intensiva (como el mencionado de la Villa 31 o en la 1-11-14 en CABA, o en Villa Azul entre las localidades de Quilmes y Avellaneda en la Provincia de Buenos Aires, o la Villa “José Luis Cabezas" entre Berisso y Ensenada en la misma provincia) es muy difícil saber la real incidencia de la enfermedad en estos barrios debido al bajo nivel de testeos existente. Otro factor es la reticencia de la población a requerir asistencia médica cuando los síntomas son leves, debido a los temores a que las viviendas sean ocupadas si deben abandonarlas al dar positivo y ser trasladados a centros de aislamiento. 
Aquí cumplir con la consigna "quedate en casa" muchas veces resulta incluso contraproducente. Las posibilidades de cumplir con el ASPO (la "cuarentena" como se le dice popularmente) no son iguales para toda la población. Y es entre los más vulnerables donde más se está sintiendo la crisis.

\section{La virtualización forzosa en la educación}

En el sistema educativo la pandemia de coronavirus implicó una virtualización forzosa de la actividad en su conjunto. En los niveles inicial, primario y secundario las actividades fueron instrumentadas en forma de "acompañamiento pedagógico" mientras que en universidades e institutos terciarios se reorganizó todo el sistema de cursadas con distintos ritmos y readecuaciones del calendario académico de acuerdo con cada institución. Cada universidad tomó autónomamente su decisión al respecto, e incluso en muchas de ellas cada facultad decidió qué rumbo tomar. Dentro de la heterogeneidad de situaciones lo común fue una precarización generalizada de la actividad docente. El estado no brindó ni conectividad gratuita ni proveyó de los medios materiales para la realización de las clases y demás actividades virtuales. Ni computadoras, ni laptops, ni tablets ni teléfonos celulares. Cada docente tuvo que recurrir para cumplir con estas tareas a los medios que tenía previamente para uso personal. En la mayoría de los casos ni siquiera las universidades obtuvieron licencias de las aplicaciones de uso masivo, debiendo recurrirse a las de uso gratuito que tienen tiempo de uso limitado y son más fáciles de hackear. Los contenidos de las materias, pensados para cursadas presenciales, debieron ser readecuados, recurriéndose a los campus o aulas virtuales que habitualmente tenían una utilización muy limitada. Aparte de las clases se multiplicaron las reuniones de planificación entre los docentes y con las autoridades, así como las tareas de capacitación en el uso de las herramientas indispensables para la virtualidad académica. Las actividades docentes se multiplicaron: no es solo 
preparar y dar las clases y evaluar del desempeño de los estudiantes, sino programarlas, grabarlas y subirlas a internet, frecuentemente con recursos limitados para hacer estas tareas. Además, muchos docentes son madres o padres, que deben acompañar las tareas escolares de sus hijos e hijas, y no cuentan con condiciones adecuadas en sus hogares para el dictado de las clases. Muchas veces, el uso de una o dos computadoras debe ser compartido por cuatro, cinco o más personas en un mismo hogar ${ }^{9}$. Esta precarización generalizada e intensificación del trabajo ha ocurrido en forma aumentada en los otros niveles educativos, donde la carga laboral se multiplicó aún en mayor medida. Sin embargo, la sobrecarga de tareas no tuvo su correlato ni en mayor retribución económica ni en medidas protectorias como el derecho a la desconexión o, como señalábamos, la provisión de medios materiales para desempeñar la actividad.

Por parte del gobierno se impulsó la modificación del artículo 109 de la ley 26.206, de Educación Nacional, conocida como “ley de educación a distancia". La modificación establece:

“Artículo 109: Los estudios a distancia como alternativa para jóvenes y adultos sólo pueden impartirse a partir de los dieciocho (18) años de edad. Para la modalidad rural y conforme a las decisiones jurisdiccionales, podrán ser implementados a partir del Ciclo Orientado del Nivel Secundario. Excepcionalmente, previa declaración fundada del Ministerio de Educación en acuerdo con el Consejo Federal de Educación, o con la jurisdicción según corresponda, cuando la escolaridad presencial - total o parcial - sea inviable, y únicamente en caso de epidemias, pandemias, catástrofes o razones de fuerza mayor que impidan la concurrencia a los establecimientos educativos, sólo en esos casos será permitido transitoriamente el desarrollo de trayectorias educativas a distancia para los niveles y las modalidades de la educación obligatoria para menores de dieciocho (18) años de edad. En tal excepcionalidad deberán adoptarse disposiciones para 
la reorganización: pedagógica - de acuerdo a los Núcleos de Aprendizaje Prioritarios - e institucional, del régimen académico y de la capacitación docente. Del mismo modo deberá atenderse la provisión de recursos tecnológicos y conectividad que promuevan la igualdad educativa con condiciones de calidad según lo establecen los artículos 80 y 84 de la presente ley; y la adopción de las condiciones de salud y seguridad en el trabajo que se requieran conforme lo establezcan las negociaciones colectivas correspondientes".

Lo cierto es que esta modificación era innecesaria a los efectos de la continuidad de las actividades que se venían realizando y abre la puerta a la utilización de la virtualidad como herramienta en caso de "fuerza mayor" por parte de los gobiernos ante huelgas o medidas de protesta de los docentes.

\section{Teletrabajo y precarización}

No solo en la docencia y la administración pública sino en una cantidad muy importante de actividades del sector privado el ASPO llevó a la generalización forzosa de modalidades de "teletrabajo" o "home office", lo que implicó una precarización generalizada de las condiciones de trabajo de quienes fueron afectados.

La misma carece en este momento de toda regulación específica, por lo que implica que se realice en las peores condiciones - sin contemplar límites a la jornada laboral ni horas extras, condiciones de trabajo y enfermedades laborales, etc.- y frecuentemente altos niveles de estrés por mayor presión de productividad.

Actualmente existen un conjunto de leyes que engloban la actividad como la Ley de Contrato de Trabajo (LCT) que junto a la Ley 25.800 -que ratifica el Convenio No 177 sobre el trabajo a domicilio de la OITy promueve la igualdad de condición de estos trabajadores con respecto a los presenciales. Ambas reglamentaciones cubren la actividad correspondiente a trabajadores contratados en relación de dependencia, 
englobando al teletrabajo, pero sin mencionarlo en forma directa, sin definirlo ni reglamentarlo específicamente. El vacío legal beneficia sin duda a las empresas, ya que el trabajador se encuentra en una situación de mayor indefensión ${ }^{10}$.

En el marco del ASPO se dictó una resolución de la Secretaría de Riesgos del Trabajo (la 21/2020) que estableció en su artículo 2 que para "quienes presten tareas desde su casa en virtud de la pandemia no les es aplicable la resolución del 2012 (1552)", única que preveía medidas mínimas de protección para esta modalidad de trabajo.

Según los datos del Centro de Implementación de Políticas Públicas para la Equidad y el Crecimiento (CIPPEC) sobre el impacto del aislamiento preventivo y obligatorio en las modalidades de empleo en Argentina el porcentaje de trabajos que tienen el potencial para realizarse desde el hogar se encuentra entre un 27 y un $29 \%$ de los totales - que se reduce a $18 \%$ si se considera la cantidad de hogares con uso efectivo de computadoras -, lo que abarcaría a 3 millones de trabajadores sobre un total de casi 12 millones. Al 27/3/20, se informaba que previamente a la pandemia había ya 970.000 personas que trabajaban desde sus casas: 170.000 directamente no asisten a la oficina o lo hacen muy de vez en cuando y 800.000 son teletrabajadores mixtos, un sistema que combina tareas a distancia con presenciales. Con el ASPO la modalidad, ya muy presente en las telecomunicaciones, el comercio, la informática y tareas de oficina en rubros diversos, se amplió exponencialmente. Ninguna medida fue tomada desde el gobierno para garantizar mínimos derechos durante la emergencia, ni cumplimiento de jornada laboral, ni derecho a la desconexión ni provisión de los materiales de trabajo por parte de las patronales.

\section{Los repartidores se organizan}

En Argentina la juventud (entre 16 y 24 años), como ocurre a nivel internacional, es el sector con mayores índices de precarización" ${ }^{11}$. Presentemos primero una radiografía de cómo estaba el empleo ju- 
venil para 2018. Los jóvenes que tenían un trabajo remunerado o buscaban tenerlo (la población económicamente activa en las estadísticas) ascendían a 2.800.000. De ellos 2.200.000 tenían un empleo, y la gran mayoría percibía un salario, dependiendo de un patrón. Casi 600.000 no encontraban trabajo. El porcentaje de jóvenes desocupados y subocupados triplica los porcentajes de la población adulta. Un $61 \%$, alrededor de 1.170 .000 jóvenes trabajadores, se desempeñaba en empleos sin registrar, mientras el promedio general era de 34\%. El promedio de rotación en el empleo era de solo 12 meses, mientras llegaba a los 26 meses entre los mayores de 25 años. Alrededor de 950.000 jóvenes son parte de quienes ni estudian ni trabajan, los llamados despectivamente "ni-ni", de los cuales dos de cada tres son mujeres. El salario de los jóvenes es un 40\% inferior al de la población adulta y solo llegaba a cubrir un tercio de la canasta familiar. Los jóvenes son también un $70 \%$ de quienes se desempeñan en agencias de empleo y tienen un 50\% más de probabilidades de sufrir accidentes laborales que la población adulta. Entre las mujeres jóvenes la mortalidad laboral es tres veces mayor que entre las adultas. La población juvenil bajo la línea de pobreza, con independencia de si trabajaba o no lo hacía, llegaba a 2.500.00012.

¿En qué actividades se desempeñan los jóvenes? Alrededor de 600.00, lo hacen en el Comercio; 380.000, en el Trabajo Doméstico, en su gran mayoría mujeres; 300.000 en la Industria; 250.000, en la Construcción; 200.000, lo hacen en Restaurantes y Hoteles; y 180.000 entre el Campo y la Pesca. Una parte creciente empezaba a hacerlo en la llamada "economía de plataformas", donde en 2019 ya trabajaban en total unas 160.000 personas (un 1\% de la fuerza de trabajo), con un porcentaje importante de jóvenes (el 90\% es menor a 60 años y un tercio es menor de 30 años) ${ }^{13}$, sobre todo concentrados en las empresas de reparto. En conjunto es una fuerza de trabajo altamente masculinizado (4 de cada 5 son hombres) y con una proporción muy alta de inmigrantes (un 20\% de la fuerza laboral). También el nivel de informa- 
lidad es muy importante. De acuerdo con la investigación encabezada por Javier Madariaga, sólo un 55\% de los encuestados afirmó realizar aportes provisionales por su actividad en la plataforma (de los cuales casi el 90\% lo hace a través del régimen de monotributo), y apenas el $40 \%$ posee una obra social a raíz de su trabajo ${ }^{14}$.

Andrea Del Bono señala las heterogeneidades de actividades que se encuadran en el "trabajo de plataforma:

"El trabajo de plataforma y sus características dependen de la forma en que se articulan una serie de elementos, de cómo se produce la interacción entre la plataforma, el cliente y el trabajador, de cómo se produce el desglose del trabajo en mínimas tareas, de la organización de los servicios bajo demanda, y de la forma en que se utiliza la subcontratación y la contratación externa. De estas articulaciones resultan una serie de acuerdos y relaciones laborales, que van desde trabajo temporal, por cuenta propia, pasando por autoempleo y el trabajo informal, hasta el trabajo a destajo y a domicilio. Dependiendo de la situación específica, el trabajo que se proporciona puede ser digital o manual, alcanzar distintos grados de calificación, y exigir una entrega local (en persona) o simplemente una actividad en línea. Las tareas más comunes incluyen: tareas profesionales (por ejemplo, desarrollo de software o diseño gráfico), transporte (por ejemplo, transporte de personas o entrega de alimentos), tareas del hogar (por ejemplo, limpieza), microtareas (por ejemplo, etiquetar imágenes en páginas web)" 15.

En el sector de reparto, donde las condiciones de precarización son superiores al promedio mencionado, ha comenzado a nivel nacional e internacional un proceso de organización y lucha que pegó un salto durante la pandemia, donde la actividad fue considerada "esencial" en numerosos países, sin que esto haya significado una mejora en las condiciones laborales, donde ni siquiera las empresas reconocen su condición de empleadoras. En Argentina el negocio se encuentra distribuido entre unas pocas empresas. Según un informe 
de la consultora Focus Market, que encabeza el economista Damián Di Pace, las aplicaciones más utilizadas son PedidosYa (40\% del total de los envíos), Rappi (15\%), Glovo (10\%), Uber Eats (7\%). El 28\% restante corresponde a apps más pequeñas y a los comercios que envían directamente a los hogares para evitar la comisión de entre un $20 \%$ a un $25 \%$ que cobran estas empresas. El uso de aplicaciones de envíos aumentó en el país cuatro veces desde el inicio del ASPO el 20 de marzo último, especialmente para las compras de productos de supermercado y de farmacia. El número total de repartidores es difícil de estimar ya que no hay números oficiales. Un artículo de Forbes calculaba unos 30.000 en diciembre de $2019^{16}$, cifra que aumentó sensiblemente durante la pandemia.

Aunque las empresas niegan la existencia de una relación laboral empleador-empleado en el sector, lo cierto es que estamos frente a lo que la Organización Internacional del Trabajo (OIT) califica como “empleo encubierto".

Este "tiene lugar cuando un trabajador es contratado como contratista independiente pero su trabajo está sujeto al control de un supervisor, como en el caso de los empleados de plantilla. La verdadera naturaleza de la relación de trabajo está encubierta para eludir la normativa laboral. Puede suponer el ocultamiento de la identidad del empleador contratando a los trabajadores a través de un intermediario, o el uso de un contrato comercial o cooperativo en lugar de un contrato de trabajo, a la vez que se dirige y vigila la actividad laboral de una manera incompatible con la situación independiente del trabajador"'7.

Es falso que los trabajadores del sector se "auto empleen" ya que las empresas controlan a quién darles los viajes de acuerdo con los algoritmos que manejan. Como se explica en un trabajo mencionado:

"son las propias plataformas las que incumplen con estos requisitos de libertad -que ellas mismas ofrecen-mediante 
la introducción de acuerdos ultraflexibles de trabajo basados en la combinación del big data con la geolocalización. Flexibilidad y autonomía no dan lugar a una articulación virtuosa en el entorno de las plataformas de reparto a domicilio. Mientras que los repartidores hacen malabarismos con sus tiempos de trabajo para obtener buenas valoraciones, la gestión algorítmica produce cierta sobrecarga de trabajo, y el trabajo en la calle produce riesgos para la salud y la seguridad que carecen de visibilidad (accidentes, asaltos, clientes agresivos, etc.). Como el trabajo de los repartidores está organizado exclusivamente a través de las plataformas, los trabajadores no cuentan con canales para transmitir dichas situaciones a las empresas" ${ }^{\prime \prime}$.

Con la pandemia, la visibilidad de las muertes de trabajadores del sector durante su actividad laboral, que hacen patente las condiciones de precariedad en que deben desempeñarse, en contraste con un discurso sobre su carácter "esencial" que no se expresa en ninguna medida de protección o ingreso suplementario, ha reforzado las tendencias a tratar de organizarse sindicalmente y expresar colectivamente los reclamos, pese a las medidas de represalias que toman las empresas. Dan cuenta de esto el surgimiento de la Asociación del Personal de Plataformas, que impulsó varias de las protestas realizadas en el país y es quien ha convocado en Argentina al paro internacional del $1^{\circ}$ de julio, realizado conjuntamente con repartidores de Brasil, Chile, México, Costa Rica, Ecuador, Guatemala y Venezuela19. Parte de quienes impulsan esta iniciativa se agrupa en La RED de precarizadxs, desocupadxs e informalxs, que también hizo su debut con actividades de protesta durante la pandemia ${ }^{20}$.

\section{¿Cuidar a los que nos cuidan?}

En todos los países ha sido destacado el papel jugado por el personal de los centros de salud, tanto públicos como privados. Los distintos gobiernos afirman que es muy importante "cuidar a los que nos 
cuidan". Sin embargo, poco se ha hecho durante la pandemia para modificar las condiciones de precarización laboral existente en el sector, desde diversas formas de contratos "basura" a bajos de salario que obligan al pluriempleo. Peor aún, han existido multitud de protestas por las condiciones generales de trabajo, en especial por la falta de material de protección para el COVID 19. En Argentina se considera a la cifra de contagios en el sector proporcionalmente alta.

En el sector salud los ritmos son extenuantes y los recursos escasos. Los reclamos por falta de EPP (equipos de protección personal), información y protocolos claros, entre otros aún continúan, y explican la alta tasa de contagios aquí existentes. Ante la situación crítica, trabajadores de la salud se vienen organizando y llevando a cabo caravanas, ruidazos y manifestaciones, como la que se realizó el pasado 30 de mayo en distintos puntos del país, como en Jujuy, Buenos Aires, Córdoba, Rosario ,Tucumán y Mendoza. Denunciaron por un lado la falta de insumos y de equipos de protección. De las pocas veces que estos Ilegan, en la mayoría los mismos son de mala calidad. También visibilizaron las condiciones de precarización laboral en las que realizan jornadas con altas cargas horarias y salarios que no alcanzan. A su vez, se movilizaron contra las judicializaciones a trabajadores de la salud que son perseguidos. El lunes 25 de Mayo más de dos mil autos transitaron las calles del centro de la ciudad de Córdoba ante la imputación de dos médicos del geriátrico Santa Lucía, Lucas Figueroa y Marcelo Lázaro, por parte de la Justicia cordobesa acusados de ser los responsables de infectar de coronavirus a los pacientes. El jueves 4 de Junio, en Jujuy, se llevó a cabo un ruidazo de los trabajadores de la salud pública. En toda la provincia denuncian la falta de insumos de protección personal, persecución sindical, precarización y achicamiento de la planta de personal. Reemplazantes denuncian que no cobran sus salarios y tampoco pueden recibir el Ingreso Familiar de Emergencia. Por el vaciamiento, falleció una joven de 21 años en la localidad de San Pedro, en dicha provincia ${ }^{21}$. 
Como la gran mayoría del sistema de salud pública depende de las provincias y municipios, los regímenes laborales dependen de resoluciones que se toman en cada provincia. En el distrito más grande del país, la Provincia de Buenos Aires, se ha negado la licencia forzosa a trabajadores en situación de riesgo, lo que ha generado muertes evitables del personal.

Hasta el miércoles 24 de junio, de acuerdo con las cifras aportadas por el Ministerio de Salud de la Nación, son 3652 los profesionales de la salud que dieron positivo en el test de COVID-19. De esos 3652 infectados, 1208 fueron dados de alta y pudieron volver a trabajar. De esos 3652 contagiados, 19 fallecieron ${ }^{22}$.

Un mes después de que se decretó la cuarentena, los profesionales de la salud infectados por COVID-19 sumaban 431 y los fallecidos eran 4. Dos meses y unos días después de aquel 20 de marzo, las cifras de trabajadores de la salud infectados por el virus se multiplicaron por 8 (3652) y los fallecidos se quintuplicaron (19).

La mayoría de los que perdieron la vida eran hombres y trabajaban en hospitales o instituciones sanitarias de la provincia de Buenos Aires. Siete de los fallecidos se desempeñaban como enfermeros.

\section{A modo de conclusión}

El gobierno de Alberto Fernández se jacta de haber priorizado la salud de la población, antes que nada, diciendo que la economía puede recuperarse pero las vidas no. También sostiene haber priorizado la atención de los sectores más vulnerables. Sin embargo, este discurso se contradice con numerosos hechos y la situación de precarización que están sufriendo amplios sectores de la clase trabajadora. Esto no era y no es inevitable. Se podía aún sin que se vote ninguna nueva ley tomar resoluciones de protección respecto de las modalidades de teletrabajo y virtualización forzosa en la administración pública y entre los docentes. Peor aún, la ley de Teletrabajo aprobada en la Cámara de Diputados, que no alcanza al sector esta- 
tal, solo será aplicada a los 90 días de terminada la emergencia por la pandemia y ya se anuncia que su texto será modificado a favor de las patronales en el Senado, con el apoyo del oficialismo peronista. También haber tomado la medida de un "salario de cuarentena" de \$30.000 por persona que quedó sin ingresos (y no los apenas \$ 10.000 por grupo familiar que otorga el IFE) en base a un impuesto a las grandes fortunas, como ha propuesto la izquierda ${ }^{23}$. Recordemos que el gobierno viene amenazando desde poco después de declarado el ASPO con presentar una iniciativa de este tipo que al día de hoy no se ha concretado. Incluso los trascendidos señalan que su finalidad no sería compensar a los trabajadores por lo perdido en la emergencia sino favorecer créditos a las PYMES, las inversiones en el sector petrolero y empezar la urbanización de los barrios populares $^{24}$. Solo uno de los tres destinos tendría que ver con necesidades de los sectores populares. Mientras desde la llegada del gobierno del Frente de Todos se pagaron alrededor de U\$S 5000 millones en pagos de una deuda externa cuya legalidad está fuertemente cuestionada, los recursos adicionales otorgados al sistema de salud han estado muy por detrás de lo necesario, y eso ha redundado directamente en una alta tasa de contagios en el personal del sector de salud, los que están en la "primera línea" del enfrentamiento contra el virus. Tampoco los trabajadores de las empresas de plataforma de reparto de alimentos y otros productos, que han visto multiplicar sus ingresos, recibieron ninguna medida de protección frente a la relación de empleo encubierto existente.

La pandemia augura tiempos compulsivos en todo el mundo. El panorama de crisis económica y social que está dejando en la Argentina es particularmente grave ${ }^{25}$, haciendo recordar la quiebra económica de 2001-2002. Si la clase trabajadora no interviene en forma independiente en el escenario político el panorama será de mayor precarización y empobrecimiento. Todos nuestros esfuerzos están encaminados a que esto no suceda. 


\section{Notas}

1 Sociólogo y Profesor de la Facultad de Ciencias Sociales de la Universidad de Buenos Aires (UBA) y de la Facultad de Humanidades y Ciencias de la Educación y de la Facultad de Trabajo Social de la Universidad Nacional de La Plata (UNLP). Dirigente Nacional del Partido de los Trabajadores Socialistas (PTS). Argentina. ORCID: https://orcid.org/0000-0002-5092-2930. chcastillo2002@yahoo.com.ar.

2 El AMBA es la zona urbana común que conforman la CABA y los siguientes 40 municipios de la Provincia de Buenos Aires: Almirante Brown, Avellaneda, Berazatagui, Berisso, Brandsen, Campana, Cañuelas, Ensenada, Escobar, Esteban Echeverría, Exaltación de la Cruz, Ezeiza, Florencio Varela, General Las Heras, General Rodríguez, General San Martín, Hurlingham, Ituzaingó, José C. Paz, La Matanza, Lanús, La Plata, Lomas de Zamora, Luján, Marcos Paz, Malvinas Argentinas, Moreno, Merlo, Morón, Pilar, Presidente Perón, Quilmes, San Fernando, San Isidro, San Miguel, San Vicente, Tigre, Tres de Febrero, Vicente López, y Zárate.

Se trata de una megaciudad que se extiende desde Campana hasta La Plata, con límite físico en el Rio de la Plata e imaginario en la Ruta Provincial 6, y recorre una superficie de $13.285 \mathrm{~km} 2$. Según el censo de 2010, cuenta con 14.800.000 habitantes, que representan el $37 \%$ de los habitantes de la Argentina. Como megalópolis, se mantiene en constante crecimiento, por lo que sus límites son cada vez más difusos desde una mirada territorial.

3 Natalia Donato, Según un informe de la UCA, en los últimos diez años se duplicó el empleo precario, Infobae, 14-05-2020, disponible en https://www.infobae. com/economia/2020/05/13/segun-un-informe-de-la-uca-en-los-ultimosdiez-anos-se-duplico-el-empleo-precario/.

4 En abril se perdieron 186.000 empleos registrados por caída de nuevas incorporaciones, Ámbito, https://www.ambito.com/economia/empleo/en-abril-se-perdieron-186000-s-registrados-caida-nuevas-incorporaciones-n5114762.

5 Ante el aumento de casos existente en el AMBA, el gobierno nacional conjuntamente con los gobiernos de la Provincia de Buenos Aires y de la Ciudad Autónoma de Buenos Aires resolvieron una vuelta atrás en las medidas de apertura de actividades entre el 1 y el 17 de julio, buscando ante todo limitar la circulación en el transporte público entre distintas jurisdicciones. En épocas normales, se trasladan diariamente para realizar sus actividades laborales alrededor de 3 millones de personas diarias hacia la Ciudad Autónoma de Buenos Aires provenientes de distintos municipios de la Provincia de Buenos Aires.

6 Según establece en su página la Administración Nacional de la Seguridad Social (ANSES) el IFE corresponde a: trabajadores y trabajadoras informales; trabajadores y trabajadoras de casas particulares; monotributistas sociales; y monotri- 
butistas de las categorías A y B. Los requisitos para obtener el beneficio son: ser argentino nativo o naturalizado y residente, con una residencia legal en el país no inferior a 2 años; tener entre 18 y 65 años de edad; que el titular o su grupo familiar no tenga ingresos provenientes de un trabajo en relación de dependencia en el sector público o privado, ser monotributista de categoría C o superior, o del régimen de autónomos, una prestación de desempleo. jubilaciones, pensiones o retiros contributivos o no contributivos nacionales, provinciales, municipales o de la Ciudad Autónoma de Buenos Aires, planes sociales, salario social complementario, Hacemos Futuro, Potenciar Trabajo u otros programas sociales nacionales, provinciales o municipales. El IFE es compatible con el cobro de la Asignación Universal por Hijo, la Asignación por Embarazo y el programa Progresar. Sin embargo a estos requisitos se sumaron otros que explican las causas de rechazo a la solicitud que sufrieron más de 3 millones de personas, además de aquellos que pudieron subsanar errores iniciales. Junto con el cobro de algún otro plan social (con la excepción de la AUH y el AE) fueron denegados los pedidos de quienes hicieron gasto con tarjeta de crédito o débito por más de $\$ 22.000$, quienes tienen otro miembro del grupo familiar que tenga el beneficio o quienes sean propietarios de una vivienda por valor de \$1.200.000 o un automóvil por valor de \$500.000.

7 Maia Jastreblansky, Coronavirus en la Argentina: en las villas bonaerenses se dificulta seguir con la cuarentena estricta, La Nación, disponible en https://www. lanacion.com.ar/politica/coronavirus-argentina-villas-bonaerenses-se-dificulta-seguir-nid2391065.

8 Respecto a los barrios populares los datos oficiales se pueden ver en https:// www.argentina.gob.ar/noticias/barrios-populares.

9 Ver al respecto AGD-UBA, DATOS DEL RELEVAMIENTO SOBRE LA SITUACIÓN DE LAS Y LOS DOCENTES EN LA PANDEMIA, 28-05-2020, disponible en http:// agduba.org.ar/datos-del-relevamiento-sobre-la-situacion-de-las-y-los-docentes-en-la-pandemia/.

10 El 25 de junio la Cámara de Diputados votó por 214 votos a favor, 29 abstenciones y 1 en contra una ley de regulación del teletrabajo que debe aún ser tratada en la Cámara de Senadores. Sin embargo, la ley, por presión de las entidades empresariales, tiene una cláusula transitoria que señala su entrada en vigencia recién a los 90 días de concluida la emergencia por la pandemia de conoravirus, con lo cual avala las arbitrariedades y precarización forzosa durante este período. En el debate de la ley, solo los diputados del Frente de Izquierda, Nicolás Del Caño y Romina Del Plá, denunciaron la existencia de esta cláusula.

11 En 2019 Nicolás Del Caño (junto a un equipo de colaboradores del cuál fui parte) publicaba un trabajo que daba cuenta de la situación laboral de la juventud en Argentina, como parte de un fenómeno internacional: "Rebelde o Precarizada. Vida 
y futuro de la juventud en tiempos de FMI. De los noventa a la era Macri", Ariel, Buenos Aires, 2019.

12 Los datos están tomados de: “Jóvenes y Trabajo”, Equipo de Mercado de Trabajo de la Dirección General de Estudios Macroeconómicos y Estadísticas Laborales del Ministerio de Trabajo, Empleo y Seguridad Social, junio de 2018. "Vulnerabilidad, precariedad y desafiliación de los jóvenes del conurbano bonaerense en la poscrisis", Universidad Nacional de San Martín, 2019. "Informe anual sobre la situación de los jóvenes en el sistema de riesgos del trabajo”, Superintendencia de Riesgos del Trabajo, 2018.

13 Madariaga, J., Buenadicha, C., Molina, E. y Ernst, C. (2019). Economía de plataformas y empleo ¿Cómo es trabajar para una app en Argentina?, CIPPEC-BID - OIT. Buenos Aires, 2019.

14 Madariaga, J., Buenadicha, C., Molina, E. y Ernst, C., Op. Cit.

15 Andrea Del Bono, Trabajadores de plataformas digitales: Condiciones laborales en plataformas de reparto a domicilio en Argentina, en Cuestiones de Sociología, n²1, 083, agosto 2019-enero 2020, ISSN 2346-8904, Universidad Nacional de La Plata, Facultad de Humanidades y Ciencias de la Educación, Departamento de Sociología.

16 "Por qué PedidosYa, Rappi y Glovo están cambiando la comida, las compras y el trabajo", Forbes Argentina, disponible en https://www.forbesargentina.com/ negocios/por-pedidosya-rappi-glovo-estan-cambiando-comida-compras-trabajo-n1172/amp.

17 Madariaga, J., Buenadicha, C., Molina, E. y Ernst, C., Op. Cit.

18 Andrea Del Bono, Op. Cit.

19 “APPs: unidad internacional para convocar a un paro el $1^{\circ}$ de Julio", La Izquierda Diario, 20-06-2020, disponible en http://www.laizquierdadiario.com/APPsunidad-internacional-para-convocar-a-un-paro-el-1o-de-Julio.

20 Jóvenes precarizados: gran repercusión mediática de la movilización nacional, La Izquierda Diario, 14-05-2020, disponible en http://www.laizquierdadiario. com/Jovenes-precarizados-gran-repercusion-mediatica-de-la-movilizacion-nacional.

21 Hay casi 1800 trabajadores de la salud contagiados de Covid-19 en Argentina, Informe del Observatorio de Salud La Izquierda Diario, 5 de junio, disponible en http://www.laizquierdadiario.com/Hay-casi-1800-trabajadores-de-la-salud-contagiados-de-Covid-19-en-Argentina. 
22 Ver Florencia Illibele, Coronavirus en Argentina: en dos meses se quintuplicaron los muertos en el área de salud y ya suman 19, Infobae, disponible en https:// www.infobae.com/sociedad/2020/06/25/coronavirus-en-argentina-en-dosmeses-se-quintuplicaron-los-muertos-en-el-area-de-salud-y-ya-suman-19/.

23 Ver Christian Castillo, El debate sobre el impuesto extraordinario a las grandes fortunas, La Izquierda Diario, 15-04-2020, disponible en http://www.laizquierdadiario.com/El-debate-sobre-el-impuesto-extraordinario-a-las-grandes-fortunas.

24 Horacio Verbitsky, La Puntita, El Cohete a la Luna, 28-06-2020, disponible en https://www.elcohetealaluna.com/la-puntita/

25 Christian Castillo, Prepararnos para la catástrofe que se avecina, Ideas de Izquierda, 24-05-2020, disponible en http://www.laizquierdadiario.com/Prepararnos-para-la-catastrofe-que-se-avecina. 